\title{
Review of ongoing initiatives to improve prescribing efficiency in China; angiotensin receptor blockers as a case history
}

\author{
W Zeng ${ }^{1}$, LL Gustafsson², M Bennie ${ }^{3,4}$, AE Finlayson", *B Godman²,3,6 \\ ${ }^{1}$ School of Management, Chongqing Jiaotong University, No.66 Xuefu Road, Nan'an District, \\ Chongqing 400074, China. Email: wenwin99@sina.com \\ ${ }^{2}$ Department of Laboratory Medicine, Division of Clinical Pharmacology, Karolinska Institutet, \\ Karolinska University Hospital Huddinge, SE-141 86, Stockholm, Sweden. Emails: \\ Lars-L.Gustafsson@ki.se; Brian.Godman@ki.se \\ ${ }^{3}$ Strathclyde Institute of Pharmacy and Biomedical Sciences, University of Strathclyde, Glasgow, UK. \\ Email: brian.godman@strath.ac.uk; marion.bennie@strath.ac.uk \\ ${ }^{4}$ Public Health and Intelligence Strategic Business Unit, NHS National Services Scotland, Edinburgh, \\ EH12 9EB, UK. Email: m.bennie@nhs.net \\ ${ }^{5}$ Green Templeton College, 48 Woodstock Road, University of Oxford, Oxford OX2 6HG, UK. Email: \\ alexanderfinlayson@gmail.com \\ ${ }^{6}$ Liverpool Health Economics, Liverpool University, Chatham Street, Liverpool L69 7ZH, UK \\ ${ }^{*}$ Author for correspondence
}

Key words: Health reforms, pharmaceuticals, drug utilisation, China, angiotensin receptor blockers

(Accepted for publication).

\begin{abstract}
Introduction: Pharmaceutical expenditure is rising by $16 \%$ per annum in China and is now $46 \%$ of total expenditure. Initiatives to moderate growth include drug pricing regulations and encouraging INN prescribing. However, no monitoring of physician prescribing quality and perverse incentives. Objectives: Assess changes in ARB utilisation and expenditure as more generics become available; compare findings to Europe. Methodology: Observational retrospective study of ARB utilisation and expenditure between 2006 and 2012 in the largest hospital in Chongqing District. Results: Variable and low use of generics versus originators with a maximum of $31 \%$ among combined single ARBs. Lower for Fixed Dose Combinations. Prices typically reduced over time, greatest for generic telmisartan (-54\%), mirroring price reductions in some European countries. However, no preferential increase in prescribing of lower cost generics. Accumulated savings of 33million CNY for this large provider if adopted European practices. Conclusion: considerable opportunities to improve prescribing efficiency in China.
\end{abstract}

\section{Introduction}

There is increasing scrutiny over pharmaceutical expenditure across countries with growth rates averaging $50 \%$ in real terms during the past decade [1,101], driven by well-known factors including ageing populations and new premium priced drugs $[1-3,101]$. This has resulted in multiple reforms across countries. Initiatives for established drugs include measures to enhance the utilisation of low cost generics versus originators and single sourced (patented) products in a class or related class where all products are seen as essentially therapeutically similar. Classes include the proton pump inhibitors (PPIs), statins and renin-angiotensin inhibitor drugs [1,3-13], with the latter including both angiotensin converting enzyme inhibitors (ACEIs) and angiotensin receptor blockers (ARBs).

Savings can be substantial with greater utilisation of generics versus originators and patented products in a class without compromising care, with prices of generics as low as $2 \%$ to $10 \%$ of prepatent loss prices in some countries [1,3-8,14-17]. Multifaceted demand-side measures to enhance their prescribing include encouraging high International non-proprietary name (INN) prescribing, 
formularies, prescribing guidance, continuous medical education, quality circles, strengthening of drug and therapeutic committees (DTCs), prescribing targets, financial incentives and prescribing restrictions [1,3-8,10-13,18,19]. Examples of the impact of multifaceted supply- and demand-side measures are included in Table 1. 
Table 1 - Influence of multiple supply- and demand-side measures on the utilisation and expenditure of PPIs, statins and renin-angiotensin inhibitor drugs among selected European countries [1,3,5-8]

\begin{tabular}{|l|l|}
\hline \multicolumn{1}{|c|}{ Country } & \multicolumn{1}{c|}{ Impact of initiatives } \\
\hline Netherlands & $\begin{array}{l}\text { Reimbursed expenditure for the PPIs fell by } 58 \% \text { in } 2010 \text { vs. } 2000 \\
\text { despite a } 3 \text { fold increase in utilisation } \\
\text { Reimbursed expendiure for the statins fell by } 14 \% \text { in } 2010 \text { vs. } 2000 \\
\text { despite a 3-fold increase in utilisation }\end{array}$ \\
\hline Sweden & $\begin{array}{l}\text { Reimbursed expenditure for the PPIs and statins decreased by } 49 \% \text { and } \\
39 \% \text { in } 2007 \text { vs. } 2001 \text { respectively despite a } 53 \% \text { and } 3.2 \text { fold increase } \\
\text { in their utilisation }\end{array}$ \\
\hline UK (Scotland) & $\begin{array}{l}\text { Reimbursed expenditure on PPIs in } 2010 \text { was } 56 \% \text { below } 2001 \text { levels } \\
\text { despite a } 3 \text { fold increase in utilisation; expenditure would have been } \\
\text { GB£159million greater in } 2010 \text { for a } 5.2 \text { million population without such } \\
\text { measures }\end{array}$ \\
& $\begin{array}{l}\text { Reimbursed expenditure on the statins in } 2010 \text { was only } 7 \% \text { above } 2001 \\
\text { levels despite a } 6.2 \text { fold increase in utilisation; expenditure would have } \\
\text { been GB£290million greater in } 2010 \text { for a } 5.2 \text { million population without } \\
\text { such measures } \\
\text { Reimbursed expenditure on the renin-angiotensin inhibitor drugs } \\
\text { remaining relatively stable between } 2001 \text { and } 2007 \text { despite a } 159 \% \\
\text { incease in utilisation }\end{array}$ \\
\hline
\end{tabular}

Considerable savings can also be achieved in low- and middle income countries from switching originators to the lowest-priced generic drugs [20-22].

China has also seen considerable increases in pharmaceutical expenditure, growing at over $16 \%$ per annum during the past decade $[22,23]$. This growth has been principally driven by increase insurance coverage. The Chinese government has introduced three different types of health insurance targeting different populations, with coverage reaching over $90 \%$ of the population by 2011 [24-26]. The ultimate goal is universal coverage by 2020 [24-29]. As a result of increased coverage, healthcare expenditure increased from $3.5 \%$ to $5 \%$ of GDP between 1995 and 2010 , equating to a ten-fold increase in per capita spending from US\$21 to 220 [26].

As a result, China has introduced a number of measures in recent years to help moderate this growth $[22,23,25,26]$. The principal measures have concentrated on trying to control pharmaceutical prices and expenditure in hospitals. This is because more than $80 \%$ of total pharmaceutical consumption is currently dispensed in public hospitals in China $[22,23,30]$. In 2010, pharmaceutical revenues for Chinese public hospitals were 405.39billion CNY (approximately US $\$ 62.4$ billion), $46 \%$ of total healthcare expenditure $[22,102]$, with out-of-pocket payments accounting for $36 \%$ of total healthcare expenditure [26]. This includes mechanisms to lower the price of drugs [22,23]. For state-priced products, the National Development and Reform Commission (NDRC) sets maximum retail prices (price caps) including mark-ups; for province- or municipality-priced products, the price management department determines the retail prices; and for other products the ex-factory and retail prices are determined by the manufacturers [22,26,31,32]. For instance, the NDRC has implemented 28 price adjustments between 1997 and 2011 to address potentially high prices for common or expensive medicines such as cardiovascular drugs or anticancer drugs $[22,33]$.

Medicines in hospitals are subject to tenders in each province and municipality with each hospital pharmacy subsequently having its own product list and prices, e.g. for cardiovascular drugs prices have changed four times between 2006 to 2011 in Chongqing Urban District alone [22,33]. Published studies have suggested these bidding processes reduced prices of essential medicines by $16.9 \%$ between 2009 and 2011 [26]. However, there are no pricing policies for generics in China unlike measures across Europe which have led to low prices [1,3-8,34]. In addition in the current system, hospitals typically use the profits from medicine procurement for their sustainability $[31,103]$, with pharmaceutical expenditure in hospitals accounting for between $41.5 \%$ to $46 \%$ of hospitals' total 
income between 2006 and 2010 [22,32,35,36,102]. This is because the financial support of the Chinese government to public hospitals declined steadily from approximately $60 \%$ of hospital revenues in 1980 s to $8.2 \%$ by 2003 . Consequently, hospitals use the revenue from drug procurement for their sustainability with a permitted $15 \%$ mark-up [26,32]. Even with measures to reduce procurement prices, the actual mark-up of medicines in hospitals in 2005 averaged approximately $42 \%$ [32]. There are also inducements for physicians to overprescribe drugs as well as prescribe drugs that produce the greatest profit for them and the hospital $[22,31]$. This situation is exacerbated by currently low salaries for physicians in China with many physicians earning $5000 \mathrm{CNY}$ (US\$780) a month or less [37].

The lack of policies have resulted in more than 5,000 pharmaceutical manufacturers in China producing mainly generics [22,32]. It is envisaged that greater transparency in pharmaceutical pricing may lead to further price reductions [26]. However, this remains to be seen.

Demand-side measures in China include the development of an essential medicine list, clinical guidance and guidelines $[23,26,35,38,103]$. However, currently there are no measures among public insurers to monitor the quality of prescribing [31,36], with emphasis principally on procurement activities. There were reforms in 2007 - the 'Prescription Management Ordinance' - specifying that prescriptions should be written by INN. However, to date there has been limited enforcement $[22,32]$. As a consequence, physicians tend to write prescriptions with the generic (INN) name and simultaneously indicate the brand or manufacturer name; alternatively, drugs are listed with the corresponding brand name or manufacturer in hospitals' IT system [22,27]. This is not helped by similar patient co-payments for an originator or generic.

The current incentives as well as limited demand-side measures have resulted in considerable irrationality in prescribing despite some measures to improve this $[26,31,32]$. This is illustrated by continued appreciable use of injectable drugs in China as well as considerable prescribing of antibiotics $[31,39]$.

These various initiatives in China translated in a variety of outputs (Box 1) when utilisation and expenditure was recently analysed for cardiovascular medicines in the Chongqing Region of China [22].

Box 1 - Findings for cardiovascular medicines in the Chongqing Region in China 2006 to 2011 [22]

- The market share of generics among 12 leading cardiovascular (CV) drugs decreased from $50 \%$ in the first half of 2006 to $34 \%$ by the end of 2011 , with the market share of originators increasing to $66 \%$ by the end of 2011 (DDD based)

- The market share of originators appreciably increased between 2006 and 2008. Narrower fluctuations after this

- Generic versions were available for all 12 drugs from 2006

- The price of originators were on average $63 \%$ higher than generic prices in 2011

- Prices of generics for the $12 \mathrm{CV}$ drugs varied from $66 \%$ to $98 \%$ price of the originator in 2011

- There was potential for considerable savings with greater use of generics if this could be engineered alongside obtaining lower prices where possible

We would like to build on these findings looking specifically at angiotensin receptor blockers (ARBs). The reasons for this are included in Box 2. 
Box 2 - Rationale for the current study researching ARBs in China $[3,10,11,14,15,18,22,32,41-43,55$ $57,106]$

- Ischaemic heart disease and cerebrovascular disease are now among the leading causes of death in China

- Previous studies have shown appreciable price reductions for generics; however, other studies have shown less of a difference

- Generic losartan recently became available in Western Europe with all angiotensin receptor blockers (ARBs) seen as essentially similar at appropriate doses

- There was considerable variation in demand-side measures among Western European countries to encourage the prescribing of losartan once generics became available, which has resulted in appreciable differences in losartan utilisation post generics without compromising care. There were also appreciable differences in generic losartan prices. Consequently, providing an opportunity to compare the findings with China

- Between 2006 and 2012, some generic ARBs alone or in fixed dose combinations (FDCs) were included in hospital lists in China providing opportunities to further evaluate generic penetration rates and savings building on Box 1

Consequently, the principal objectives of this study are to assess changes in ARB utilisation in China as more generic ARBs are incorporated into hospital procurement lists, which includes assessing changes in the utilisation of originator versus generic ARBs over time; similarly ARB Fixed Dose Combinations (FDCs). Secondly, assess changes in ARB and ARB FDC expenditure over time as well as for generic and originator ARBs and ARB FDCs. This includes price reductions over time

We will subsequently compare the findings with Western European countries with China striving for universal coverage, which is routine among Western European countries. This will provide a basis for suggesting potential future reforms that have been successful in Europe for the authorities in China to consider to achieve their aims without further growth at over $16 \%$ per annum.

We would expect to see greater prescribing of originators than generics building on our earlier findings (Box 1). In addition, variable and sometimes limited price reductions for generics versus originators and versus pre-generic inclusion prices. We expect price reductions to be less than those seen among some Western European countries for high volume generics including losartan (Box 1). This is despite multiple generic ARBs being available in China (Table 2) [102].

Table 2 - Registered number of approvals for production of generic angiotensin receptor blockerss in China in October 2013 [107]

\begin{tabular}{llllll}
\hline ARBs & Losartan & Valsartan & Irbesartan & Telmisartan & Candesartan \\
\hline $\begin{array}{l}\text { Registered numbers of } \\
\text { approval }\end{array}$ & 34 & 43 & 41 & 117 & 32 \\
\hline
\end{tabular}

\section{Methodology}

This was an observational retrospective study of prescriptions dispensed over a seven year period between 2006 and 2012 [40]. This includes the time period of the previous study (Box 1). This methodology was chosen since multiple supply- and demand-side measures have been introduced during this period in China making it difficult to perform an interrupted time series analysis. In addition, there have been multiple changes to the procurement of single and ARB FDCs over time (Table 3). 
Table 3 - Procurement of single ARBs and ARB fixed-dose combinations (FDCs) in the Chongqing District from 2006 to 2012

\begin{tabular}{|l|c|c|}
\hline \multicolumn{1}{|c|}{ ARB single } & Date originator available & $\begin{array}{c}\text { Date when generics first part of } \\
\text { hospital procurement }\end{array}$ \\
\hline Candesartan & Not available & Available in 2006 \\
\hline Irbesartan & 2006 & 2007 (October) \\
\hline Losartan & 2006 & 2012 (March) \\
\hline Telmisartan & 2006 & Available in 2006 \\
\hline Valsartan & 2006 & Available in 2006 \\
\hline ARB FDCs & & 2008 (March) \\
\hline Irbesartan FDC & 2006 & 2010 (May) \\
\hline Losartan FDC & 2006 & Not available \\
\hline Valsartan FDC & 2006 & . \\
\hline
\end{tabular}

NB Generic ARBs and FDCs may be available in China during previous years. However, not included in the procurement process in view of the considerable data that must be provided as part of tendering

Typically for these types of drug utilisation analysis, data is obtained from health authority, health insurance or pharmacy databases [5-8,10,11,15,41-43]. However in China, most drug utilisation studies are performed with data from hospitals as they incorporate both inpatient and outpatient data $[22,44]$. In addition, as mentioned, they account for $80 \%$ of total drugs currently dispensed in China [22]. This is in view of the convenience of hospital dispensing, physician recommendations, possibility of nonstandardized prescriptions and greater assurance of pharmaceutical quality in hospitals [32]. The quality of pharmaceuticals in hospitals is enhanced by strict quality control as part of the tendering process [32]. This builds on reforms to improve the manufacturing standards of generic drugs in China implemented from 2000 onwards [26], e.g. in 2009 all medicines on the Chinese Essential Medicines List (EML) were required to undergo quality sampling and testing at the provincial level at least annually and at the central level at least every three years to be considered for procurement [26].

Consequently, hospital procurement data is currently the optimal source of drug utilisation data in China. Accurate data on hospital tendering and procurement is especially important for this type of analysis given the profit hospitals make from medicines [31,32]. This data is not always available from some commercial sources, which just provide maximum retail price data [23]. Hospital procurement prices are also not always captured in health insurance data. In addition, hospitals may procure medicines that are not currently reimbursed. As a result, further reducing the utility of health insurance data as a data source for comprehensive drug utilisation studies in China.

Chongqing is a municipality directly under China's central government, with a total population of 28.8 million people (2010 census). In the urban district in Chongqing City, the main public general hospitals include three hospitals affiliated to the Third Military Medical University, two hospitals affiliated to Chongqing Medical University, and 10 municipal hospitals. Every hospital may include different generic drugs, but with the same originator equivalents as part of the tendering process to obtain good prices [22]. However, in view of the complexity of the procurement process only the largest hospitals tend to have a comprehensive range of products available for prescribing.

In view of these factors, we chose the largest hospital in Chongqing District to conduct our study. This is because it is one of the largest hospitals in Southwest China, has a wide range of medicines available for prescribing, can provide comprehensive datasets on both utilisation and expenditure and is a typical health provider to the public. The dataset was obtained from the magazine company of China Pharmacy. The company is located in Chongqing and is able to collect detailed information from large hospitals in southwest China through co-operation with public hospitals. The data contains all individual drug information including product names, purchase dates, dosage forms, specifications, manufacturers, unit prices and volumes. This is an authoritative source for drug utilisation statistics in China, which is regularly audited. We used a similar approach in previous studies [22]. 
The Chinese currency Renminbi "yuan" (CNY) was used to determine expenditure and expenditure/ DDD for ARBs and ARB FDCs over time. These were not adjusted for inflation or deflation during this period as we wanted to compute actual changes over time as a result of the tendering process. This is because most health authorities typically decrease prices when budgets are being exceeded $[45,46]$ making adjustments based on factors such as retail price indexes or purchasing price parity difficult to justify when reviewing pharmaceutical prices. This is in line with previous studies [5$8,10,11,41,42]$. We have also not converted CNY data to either US $\$$ or Euros during the course of the study as we did not want the pricing data influenced by currency fluctuations especially during the recent financial crises in Europe and the US. Originator ARBs are referred to as products currently or previously possessing intellectual property (patent), which are either from multinational companies or manufactured by joint ventures in China founded by multinational pharmaceutical companies. Generic drugs are domestic products produced by Chinese enterprises with local investment, including stateowned and private enterprises. There is strong competition with a number of manufacturers (Table 2).

Five single ARBs and three ARB FDCs were available in the target hospital (ATC C09CA01 to 09, C09DA01 to 05, C09DX01 to 03 [104]) between 2006 and 2012 (Table 3). Utilisation was measured in terms of Defined Daily Dose, with DDDs defined as 'the average maintenance dose of a drug when used in its major indication in adults', with this measure recognised as the international standard to assess utilisation patterns within and between countries [105]. The data was subsequently aggregated for analysis. 2011 DDDs were used in line with international guidance $[47,48,105]$. The WHO methodology used to calculate the DDDs for combination products, based on the principle of counting this as one dose [105].

We subsequently divided ARBs into single and ARB FDCs as ARB FDC utilisation varied considerably among Western European countries, ranging from $2 \%$ to $3 \%$ of ARB/ losartan utilisation in the UK to $50 \%$ in Austria [10,41-43]. This was due to issues such as the extent of increased compliance in practice, economics as well as access to diuretics.

A narrative review of published studies to appraise the utilisation and expenditure of ARBs among selected Western European countries was undertaken by one of the co-authors (BBG). The studies selected were based on multiple publications that the co-authors were involved with providing exemplars of potential measures the authorities in China could consider as they move towards universal coverage.

\section{Results}

\section{Utilisation}

There was an appreciable increase in the prescribing of ARBs alone or as FDCs, rising 12 fold from just over 209,000 DDDs in 2006 to 2.45million in 2012 across all products (Figure 1). 
Figure 1 - Utilisation of single and FDC ARBs (DDDs) between 2006 and 2012 in the Chongqing District from 2006 to 2012

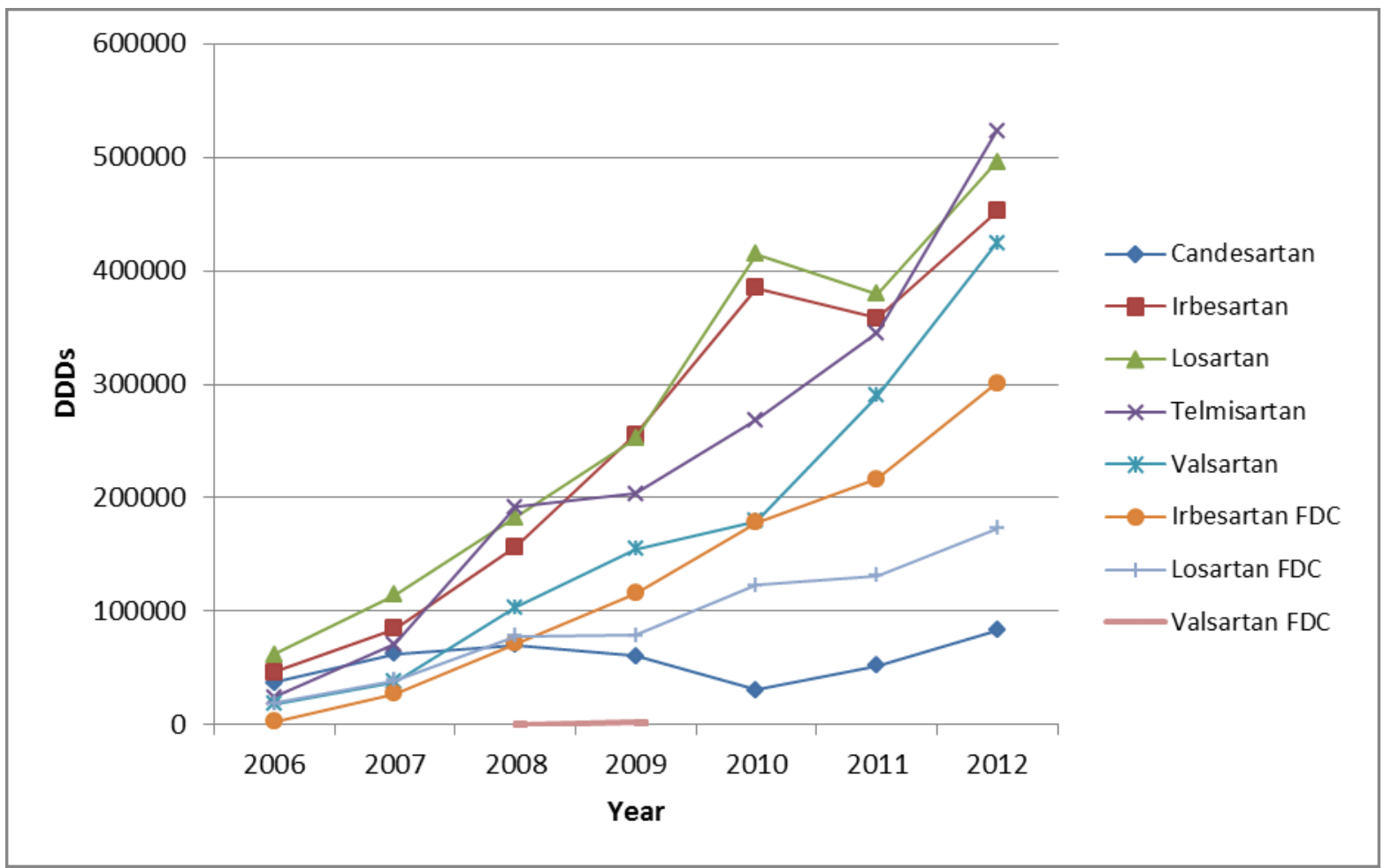

NB. FDCs = Fixed Dose Combinations.

The greatest increase in utilisation was seen for both telmisartan and valsartan among the single ARBs and for irbesartan among the FDCs (Figure 1, Table 4). However, there was variable use of generic versus originator ARBs, i.e. there was a rapid increase in the use of generic irbesartan peaking at $44 \%$ of total irbesartan in 2009 before declining to $33 \%$. A similar pattern was seen for telmisartan peaking at $40 \%$ of total telmisartan utilisation in 2011 before falling to $30 \%$ in 2012 . There was also an increase in generic candesartan in 2012 vs. 2006, although this varied by year (Figure 1) resulting in its share of total single ARBs falling from $20 \%$ in 2006 to between $2 \%$ to $4 \%$ between 2010 and 2012 (Figure 1, Table 4).

The variable use of generics among the single ARBs led to their overall utilisation increasing from $24 \%$ of total single ARBs in 2006 to $31 \%$ in 2008 before falling to between $22 \%$ and $24 \%$ between 2010 and 2012 (Table 4). This was despite increasing availability of generic ARBs (Tables 2 and 3).

There was also a 21.5 fold increase in ARB FDC utilisation between 2006 and 2012, greatest for irbesartan FDC (108 fold) (Figure 1, Table 4). As a result, there was increasing use of ARB FDCs as a $\%$ of total ARBs, rising from $11 \%$ in 2006 to stabilising at $19 \%$ to $20 \%$ between 2010 and 2012 . There was also increasing use of generic ARB FDCs reaching 19\% of total ARB FDCs in 2012. 
Table 4 - Consolidated utilisation of single and FDC ARBs (in DDDs) including generics and originators in the Chongqing District from 2006 to 2012

\begin{tabular}{|c|c|c|c|c|c|c|c|c|}
\hline Single ARBs & 2006 & 2007 & 2008 & 2009 & 2010 & 2011 & 2012 & $\begin{array}{c}\begin{array}{c}\text { Degree of } \\
\text { change }\end{array} \\
\end{array}$ \\
\hline Candersartan Generic & 36960 & 62580 & 70560 & 60480 & 30880 & 52400 & 83190 & 2.3 \\
\hline \multicolumn{9}{|l|}{ Losartan } \\
\hline Losartan - Originator & 61740 & 114597 & 182700 & 252210 & 414400 & 379400 & 431340 & \\
\hline Losartan - Generic & & & & & & & 64400 & \\
\hline Losartan - Total & 61740 & 114597 & 182700 & 252210 & 414400 & 379400 & 495740 & 8.0 \\
\hline$\%$ Generic & & & & & & & 13 & \\
\hline \multicolumn{9}{|l|}{ Irbesartan } \\
\hline Irbesartan - Originator & 46550 & 80500 & 88802 & 143640 & 230440 & 239400 & 302400 & \\
\hline Irbesartan - Generic & & 4200 & 67800 & 111600 & 154410 & 118800 & 150000 & \\
\hline Irbesartan-Total & 46550 & 84700 & 156602 & 255240 & 384850 & 358200 & 452400 & 10 \\
\hline \% Generic & & 5 & 43 & 44 & 40 & 33 & 33 & \\
\hline \multicolumn{9}{|l|}{ Telmisartan } \\
\hline Telmisartan - Originator & 22148 & 50218 & 117600 & 125020 & 162400 & 207872 & 366800 & \\
\hline Telmisartan-Generic & 1764 & 21000 & 74368 & 78400 & 106400 & 137200 & 156450 & \\
\hline Telmisartan - Total & 23912 & 71218 & 191968 & 203420 & 268800 & 345072 & 523250 & 22 \\
\hline$\%$ Generic & 7 & 29 & 39 & 39 & 40 & 40 & 30 & \\
\hline \multicolumn{9}{|l|}{ Valsartan } \\
\hline Valsartan - Originator & 12362 & 29750 & 100863 & 147210 & 168000 & 280980 & 412160 & \\
\hline Valsartan-Generic & 5698 & 8400 & 2800 & 7350 & 11200 & 9100 & 12075 & \\
\hline Valsartan-Total & 18060 & 38150 & 103663 & 154560 & 179200 & 290080 & 424235 & 23.5 \\
\hline \% Generic & 32 & 22 & 3 & 5 & 6 & 3 & 3 & \\
\hline \multicolumn{9}{|l|}{ Combined total } \\
\hline Total Generic Single ARBs & 44422 & 96180 & 215528 & 257830 & 302890 & 317500 & 466115 & 10.5 \\
\hline Total Single ARBs & 187222 & 371245 & 705493 & 925910 & 1278130 & 1425152 & 1978815 & 11 \\
\hline \% Generic & 24 & 26 & 31 & 28 & 24 & 22 & 23 & \\
\hline \multicolumn{9}{|l|}{ FDC ARBs } \\
\hline \multicolumn{9}{|l|}{ Irbesartan FDCs } \\
\hline Irbesartan FDC-Originator & 2800 & 27314 & 58100 & 92960 & 133560 & 166320 & 223440 & \\
\hline Irbesartan FDC-Generic & & & 13510 & 23100 & 44520 & 50400 & 77840 & \\
\hline Irbesartan FDC - Total & 2800 & 27314 & 71610 & 116060 & 178080 & 216720 & 301280 & 108 \\
\hline$\%$ Generic FDC & & & 19 & 20 & 25 & 23 & 26 & \\
\hline \multicolumn{9}{|l|}{ Losartan FDCs } \\
\hline Losartan FDC-Originator & 19306 & 38850 & 78400 & 79100 & 119490 & 121800 & 160370 & \\
\hline Losartan FDC-Generic & & & & & 3500 & 9800 & 12880 & \\
\hline Losartan FDC - Total & 19306 & 38850 & 78400 & 79100 & 122990 & 131600 & 173250 & 9 \\
\hline \% Generic FDC & & & & & 3 & 7 & 7 & \\
\hline Valsartan FDC - originator & & & 350 & 1960 & & & & \\
\hline \multicolumn{9}{|l|}{ Combined total } \\
\hline Total generic FDCs & & & 13510 & 23100 & 48020 & 60200 & 90720 & \\
\hline Total FDCs & 22106 & 66164 & 150360 & 197120 & 301070 & 348320 & 474530 & 21.5 \\
\hline$\%$ Generic FDCs & & & 9 & 12 & 16 & 17 & 19 & \\
\hline \multicolumn{9}{|l|}{ All ARBs } \\
\hline Total ARBs (all) & 209328 & 437409 & 855853 & 1123030 & 1579200 & 1773472 & 2453345 & 12 \\
\hline Total single ARBs (\%) & 89 & 85 & 82 & 82 & 81 & 80 & 81 & \\
\hline
\end{tabular}

NB. FDCs $=$ Fixed Dose Combinations. $\%$ Single ARBs $=\%$ single ARBs vs. total ARBs

\section{Expenditure}

Total ARB expenditure (single and FDCs) also increased appreciably, rising from just over 1 million CNY in 2006 to 9.87 million CNY in 2012 (Figure 2). 
Figure 2 - Total expenditure of ARBs (single and FDCs) 2006 to 2012 in Renminbi "yuan" (CNY) in the Chongqing District from 2006 to 2012

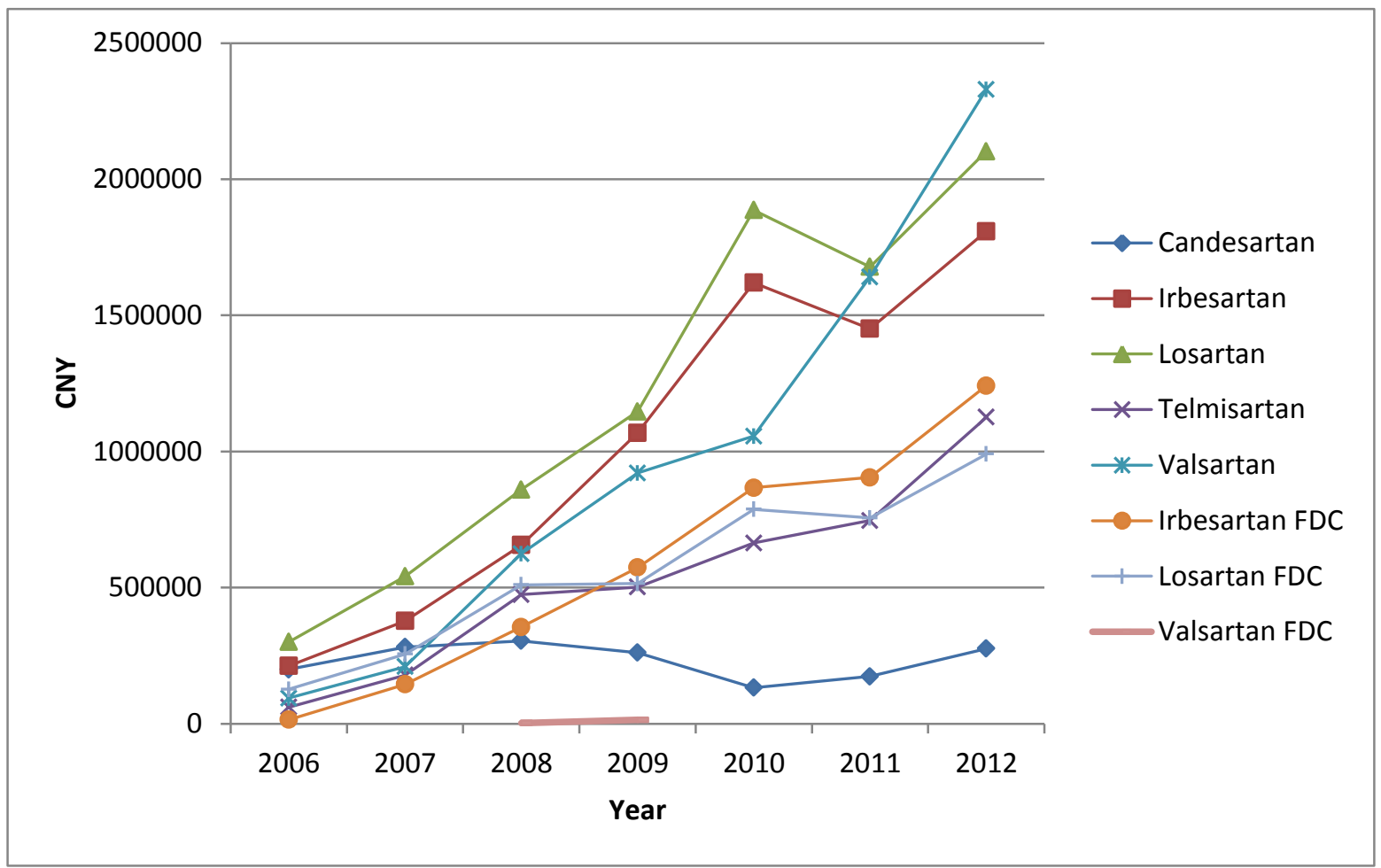

NB. FDCs $=$ Fixed Dose Combinations

The lower increase in total expenditure ( 9.8 fold) versus utilisation ( 12 fold) was helped by reducing expenditure/ DDD for the various ARBs (Table 5). However, there was only a marginal decrease for single originator ARBs combined at $7 \%$ in 2012 vs. 2006 compared with a $44 \%$ procured price reduction for generics. This resulted in an overall $17 \%$ price reduction for single ARBs combined between 2006 and 2012 (Table 5).

There was also considerable variation in procured price reductions for individual generic ARBs over the course of the study. These ranged from $22 \%$ for generic valsartan to $39 \%$ for candesartan and $54 \%$ for telmisartan. Expenditure/ DDD for generic irbesartan was $33 \%$ below pre-inclusion prices in 2012 (Table 5). There were also variable differences in procured prices of generic versus originator single ARBs. This was greatest for valsartan reaching $59 \%$ in 2012 . This compares to a maximum of $32 \%$ for irbesartan in 2012 , with the difference steadily growing over time. There was considerable variation for telmisartan, ranging from a $31 \%$ increase in 2006 to a $39 \%$ decrease in 2012, with again a greater decrease in recent years.

There was a greater procured price reduction for combined originator FDCs at $21 \%$ during the study period versus single originator ARBs at 7\%. Expenditure/ DDD for generic FDCs combined reduced by $49 \%$ in 2012 vs. combined originator FDC prices in 2006 (Table 5).

One reason for increased utilisation of irbesartan FDCs in recent years (Table 4) could be the limited procured price differential between originator and generic single drugs and corresponding FDCs in 2011 and 2012, with a maximum 18\% difference between originator single and FDCs in 2007. However, there were no appreciable price differences between generic single and FDC irbesartan between 2008 and 2012. In fact in 2011 expenditure/ DDD for the generic FDC irbesartan was lower than single irbesartan (Table 5). 
Table 5 - Expenditure/ DDD for single ARBs (generic and originator) and FDC ARBs (generic and originator) in the Chongqing District from 2006 to 2012

\begin{tabular}{|c|c|c|c|c|c|c|c|c|c|}
\hline ARB single & 2006 & 2007 & 2008 & 2009 & 2010 & 2011 & 2012 & $\begin{array}{c}\% \text { change } \\
2012 \text { vs. } 2006\end{array}$ & $\begin{array}{l}\% \text { change in } \\
2012 \text { vs. pre- } \\
\text { patent loss }\end{array}$ \\
\hline Candesartan (generic) & 5.397 & 4.492 & 4.310 & 4.310 & 4.294 & 3.313 & 3.315 & \begin{tabular}{|r|}
-39 \\
\end{tabular} & \\
\hline Irbesartan-Originator & 4.562 & 4.489 & 4.466 & 4.466 & 4.466 & 4.466 & 4.466 & -2 & -2 \\
\hline Irbesartan-Generic & & 3.827 & 3.825 & 3.825 & 3.825 & 3.212 & 3.057 & & -33 \\
\hline Irbesartan \% Difference & & -15 & -14 & -14 & -14 & -28 & -32 & & \\
\hline Losartan (Originator) & 4.865 & 4.719 & 4.705 & 4.546 & 4.552 & 4.423 & 4.169 & -14 & -6 \\
\hline Losartan (Generic) & & & & & & & 4.720 & & 7 \\
\hline \% Losartan Difference & & & & & & & 13 & & \\
\hline Telmisartan-Originator & 2.478 & 2.480 & 2.439 & 2.439 & 2.439 & 2.439 & 2.439 & -2 & \\
\hline Telmisartan-Generic & 3.239 & 2.566 & 2.516 & 2.516 & 2.516 & 1.743 & 1.479 & -54 & \\
\hline Telmisartan \% Difference & 31 & 3 & 3 & 3 & 3 & -29 & -39 & & \\
\hline Valsartan - Originator & 6.247 & 6.232 & 6.111 & 6.111 & 6.111 & 5.761 & 5.585 & -11 & \\
\hline Valsartan-Generic & 2.925 & 2.834 & 2.834 & 2.834 & 2.630 & 2.412 & 2.286 & -22 & \\
\hline Valsartan \% Difference & -53 & -55 & -54 & -54 & -57 & -58 & -59 & & \\
\hline Total Single ARBs - originator & 4.516 & 4.407 & 4.407 & 4.480 & 4.449 & 4.399 & 4.195 & -7 & \\
\hline Total single ARBs - Generic & 4.994 & 3.898 & 3.519 & 3.512 & 3.369 & 2.571 & 2.783 & -44 & \\
\hline Total single ARBs & 4.629 & 4.275 & 4.136 & 4.210 & 4.193 & 3.992 & 3.862 & -17 & \\
\hline \multicolumn{10}{|l|}{ ARB FDCs } \\
\hline Irbesartan FDC-Originator & 5.196 & 5.296 & 5.196 & 5.196 & 5.184 & 4.471 & 4.471 & -14 & -16 \\
\hline Irbesartan FDC-Generic & & & 3.913 & 3.913 & 3.913 & 3.194 & 3.114 & & -41 \\
\hline \% Irbesartan Difference & & & -25 & -25 & -25 & -29 & -30 & & \\
\hline Losartan FDC-Originator & 6.548 & 6.577 & 6.507 & 6.507 & 6.476 & 5.892 & 5.863 & -10 & -10 \\
\hline Losartan FDC-Generic & & & & & 3.897 & 3.897 & 3.897 & & -40 \\
\hline$\%$ Losartan FDC Difference & & & & & -40 & -34 & -34 & & \\
\hline Valsartan FDC - originator & & & 6.963 & 6.963 & & & & & \\
\hline Total generic FDCs & & & 3.913 & 3.913 & 3.912 & 3.309 & 3.225 & & -49 \\
\hline Total originator FDCs & 6.377 & 6.048 & 5.952 & 5.812 & 5.794 & 5.072 & 5.053 & -21 & \\
\hline
\end{tabular}

NB. FDCs = Fixed Dose Combinations. Pre-patent loss $=$ pre-procurement of generics (although may have been available for procurement before this)

There were considerable differences in the utilisation of losartan among selected Western European countries post generics (Table 6). Similarly for price reductions for generic losartan over time versus pre-patent loss prices. 
Table 6 - Differences in demand-side measures among selected European countries to enhance losartan utilisation post generics and their impact [10,11,39,41,55,56]

\begin{tabular}{|c|c|c|c|c|}
\hline Country & Summary demand-side measures & $\begin{array}{l}\text { \% losartan } \\
\text { utilisation } \\
\text { time } 0\end{array}$ & $\begin{array}{l}\text { \% losartan } \\
\text { utilisation } \\
\text { at the } \\
\text { study end }\end{array}$ & $\begin{array}{l}\text { \% price } \\
\text { generic } \\
\text { losartan } \\
\text { vs. } \\
\text { originator }\end{array}$ \\
\hline Austria & $\begin{array}{l}\text { - } \quad \text { Prescribing restrictions removed for losartan } \\
\text { but not the other ARBs } \\
\text { - Potential sanctions for physician abuse } \\
\text { including financial penalties }\end{array}$ & $10 \%$ & $17 \% *$ & $17 \%$ \\
\hline Belgium & $\begin{array}{l}\text { - Prescribing restrictions removed for losartan } \\
\text { but not for patented ARBs } \\
\text { Patented ARBs still needed prior approval } \\
\text { from health insurers - otherwise a } 100 \% \text { co- } \\
\text { payment }\end{array}$ & $20 \%$ & $24 \% *$ & $54 \%$ \\
\hline Denmark & $\begin{array}{l}\text { Delisting of all other ARBs other than } \\
\text { losartan from the reimbursed list } \\
\text { Patients can be prescribed another ARB. } \\
\text { However the prescription must be justified } \\
\text { and accepted - otherwise } 100 \% \text { co-payment }\end{array}$ & $35 \%$ & $93 \% *$ & $\begin{array}{l}12 \% \text { (total } \\
\text { losartan) }\end{array}$ \\
\hline Ireland & - $\quad$ No specific activities undertaken & $24 \%$ & $23 \%$ & $56 \%$ \\
\hline Scotland & $\begin{array}{ll}- & \text { No specific activities undertaken } \\
\text { - } & \text { However, losartan } 99 \% \text { generic due to high } \\
& \text { voluntary INN prescribing }\end{array}$ & $33 \%$ & $34 \%$ ** & $12 \%$ \\
\hline $\begin{array}{l}\text { Spain } \\
\text { (Catalonia) }\end{array}$ & - $\quad$ No specific activities undertaken & $17 \%$ & $19 \%$ & $32 \%$ \\
\hline Sweden & $\begin{array}{l}\text { Multiple demand-side measures including } \\
\text { formularies recommending losartan; } \\
\text { academic detailing; prescribing targets for \% } \\
\text { losartan, therapeutic switching programmes } \\
\text { among some Counties (regions) and } \\
\text { physician or practice based financial } \\
\text { incentive schemes } \\
\text { Ongoing compulsory generic substitution in } \\
\text { pharmacies (resulting in losartan } 97 \% \\
\text { generic) } \\
\text { From May 2011, prescribing restrictions lifted } \\
\text { for losartan but not the other ARBs }\end{array}$ & $27 \%$ & $39 \% *$ & $10 \%$ \\
\hline
\end{tabular}

NB. Utilisation measured in DDDs and \% refers to \% losartan vs. other single ARBs. Time $0=$ time when generic losartan first reimbursed. Study end varied from 13 to 30 months post generic losartan. \% price generic losartan $=\%$ price by the study end vs. the pre-patent loss price of the originator (typically reimbursed expenditure/ DDD). ARBs $=$ angiotensin receptor blockers. ${ }^{*}=$ statistically significant difference. ${ }^{* *}$ Not statistically significant

A similar situation was seen in one Primary Care Organisation in the UK to that in Scotland and Sweden $[10,15,43]$. Initially, there was no immediate change in losartan utilisation following generics with no specific demand-side measures similar to Scotland. However, subsequent multiple demandside measures similar to Sweden (Table 6) resulted in losartan increasing from $26 \%$ of all single ARBs to $65 \% 7$ months later, leading to appreciable savings [15].

\section{Discussion}

We will initially discuss utilisation and expenditure patterns in the Chongqing District before comparing the findings with Western European countries (Table 6) as a basis for suggesting future initiatives in the region. As expected, there was variable utilisation of originator ARBs as more multiple sourced ARBs become available (Tables 3 and 4). 
However, there appeared to be variable rationality in prescribing with the utilisation of both valsartan (most expensive originator) and telmisartan (cheapest originator varying between $56 \%$ to $60 \%$ lower than valsartan between 2010 and 2012) growing substantially during the study period with telmisartan accounting for $26 \%$ of total single ARBs by 2012 and valsartan $21 \%$ (Tables 4 and 5 ). In addition, the utilisation of both candesartan and irbesartan, with the prices of originators between valsartan and telmisartan, decreased as a percentage of total single ACEls during the study period (Tables 4 and 5). This irrationality continued with generic ARBs with their utilisation reaching a maximum $28 \%$ to $31 \%$ of total single ARBs between 2008 and 2009 before falling to $22 \%$ to $24 \%$ between 2010 and 2012 (Table 4), with the price difference between the most expensive originator ARB and cheapest generic ARB being 59\% in 2010 and $74 \%$ in 2012 (Table 5).

This was different for the FDCs. The combined utilisation of generic FDCs rose steadily throughout the study, reaching $19 \%$ of total ARB FDCs in 2012 (Table 4). Overall, there was a steady increase in FDC utilisation, stabilising at $19 \%$ to $20 \%$ of total ARBs by 2012 (Figure 1, Table 4). This may be facilitated by similar prices for single ARBs and FDCs in some cases as seen with irbesartan (Table 5). However, it is difficult to comment further without specific research.

The various findings appear to confirm continued irrationality in the prescribing of single ARBs, mirroring the findings in other classes and with injectables versus oral drugs $[22,31,39,49]$. Having said this, there appears to be progress with obtaining reasonable price reductions for generics versus originators in hospitals in China, building on the many supply-side measures and initiatives described earlier. This can be seen with procured price reductions for generic single ARBs versus pre-patent loss prices (Table 5) matching some of those seen among some Western European countries (Table 6 ). This can also be seen with a $54 \%$ reduction in the procured price of generic telmisartan over time as well as a $33 \%$ to $41 \%$ price reduction for irbesartan generics and irbesartan FDCs respectively in 2012 vs. pre-patent loss prices. We believe the procured price reduction for generic temisartan would have been greater if we were able to obtain earlier procured prices. This matched some of the price reductions seen with the earlier research (Box 2).

However, we believe there are still opportunities for further price reductions to match those for generic losartan in Denmark, Sweden and the UK (Scotland) (Table 6). Potential initiatives could include new regulations encouraging greater transparency in the pricing of generics. In the UK, this resulted in the prices of generics falling by $32.4 \%$ in the first year of the introduction and generic simvastatin just $3 \%$ of pre-patent loss prices in recent years $[1,3,7,34]$.

There are also considerable opportunities to enhance the utilisation of low cost generics versus originators especially following the reforms to improve manufacturing standards for generics $[26,32]$. However, it is likely future demand-side measures will have only limited success unless the perverse incentives for physicians and hospitals are substantially reduced, which currently encourage the prescribing and dispensing of premium priced originators versus generics (Tables 4 and 5). Once addressed, potential demand-side measures could include greater enforcement of INN prescribing. Voluntary INN prescribing in Scotland, achieved through a variety of demand side measures, including physician training in medical schools and follow-up in ambulatory care, resulted in INN prescribing rates of $98 \%$ to $99 \%$ of total utilisation among a range of classes and drugs [34]. There are also potential measures to enhance the rational use of medicines building on the essential medicine list concept $[26,31]$. This includes encouraging the preferential prescribing of low cost multiple sourced drugs versus more expensive originators. Restricting prescribing choices will enhance physician familiarity with the medicines they prescribe. As a result, reduce potential adverse drug reactions and drug: drug interactions as well as strengthening the procurement process. This was the philosophy behind the generation of the Wise List in the Stockholm Healthcare Region, which contains approximately 200 drugs including first and second line choices covering most of the needs in ambulatory care $[4,19,50]$. An additional 100 drugs are included in a separate list reserved for common needs in specialist in- and out-patient care. High adherence rates at 80 to $90 \% \%$ to the voluntary Wise List are enhanced by the involvement of prescribers in the selection process, a comprehensive communication programme including a separate list for both patients and physicians, physician trust in the guidance as well as regular feedback [4, 19,50]. Increased adherence also reduces costs $[4,16,19]$. There are similar examples in Spain and Scotland $[7,34,50]$.

Accepted, peer-reviewed author manuscript of the following article: Zeng, W., Gustafsson, L. L., Bennie, M., Finlayson, A. E., \& Godman, B (2015). Review of ongoing initiatives to improve prescribing efficiency in China; angiotensin receptor blockers as a case history. Expert Review of Pharmacoeconomics and Outcomes Research, 15(1), 157-169. 10.1586/14737167.2015.963557 
Such a system could be introduced in Chongqing District along with continuous medical education and strengthening of hospital DTCs, providing an exemplar to other provinces and municipalities throughout China as they tackle similar issues. However, this will need strong leadership including instigating quality measures and involving prescribers to attain success [51]. Restricting the formulary to just one ARB and one ARB FDC based on the cheapest ARB (telmisartan for single ARBs and irbesartan for FDCs) would have saved an accumulated17million CNY for this leading hospital alone between 2006 and 2012. This is in line with Denmark as well as Sweden and NHS Bury (UK) with their active switching policies along with other measures (Table 6) without affecting care $[10,11,14,15,17]$. Accumulated savings increase to 33 million CNY with generic pricing similar to Scotland (Table 6).

We believe these findings are generalizable to other classes and other hospitals in China given our methodology as well as the current regulations and tendering system in China. However, this remains to be seen and is a recognised weakness of our approach. Another weakness of our paper is that we have not accessed patient records to see if the changes in ARB utilisation patterns affect subsequent quality of care. However, we do not believe this will be the case based on the findings that all ARBs are seen as essentially similar in clinical practice at appropriate doses [14-17].

Never-the-less, we believe our findings that ongoing reforms in China are leading to price reductions, mirroring those seen in other countries, are justified. There is still though a considerable opportunity for the hospitals and authorities in China to achieve further substantial price reductions for generics as well as enhance their use. Both will be needed if China is to achieve its aim of universal coverage without further substantial increases in pharmaceutical expenditure. We believe this can be achieved through active formulary management and the increase in physician continuous medical education including benchmarking physician prescribing similar to practices seen among Western European countries. However for long term sustainability, there must be changes in the remuneration system for hospitals and physicians. This builds on current contracting initiatives in some hospitals and regions [52]. There must also be regulations and laws to reduce unethical practices including rebate practices similar to recent regulations and laws in Europe, Korea and the US [6,53,54].

In conclusion, we believe we have demonstrated that there is still considerable irrationality in prescribing in China despite recent measures and that there are considerable opportunities to save costs without compromising care. We believe China can achieve this by learning from exemplars among Western European countries and successfully implementing these. However, this needs changes in the remuneration system to hospitals and physicians. Without such measures, China is unlikely to attain its goal of universal insurance coverage by 2020.

\section{Key issues}

- Pharmaceutical expenditure rose steadily at over $16 \%$ per annum during the past decade with medicines accounting for $46 \%$ of total expenditure in $2010.80 \%$ of medicines are currently dispensed in hospitals

- Physicians and hospitals currently use the prescribing and procurement of medicines to enhance their income, with the average mark-up on medicines in hospitals at $42 \%$ in 2005 . This has resulted in considerable irrationality in prescribing despite initiatives such as Essential Medicine Lists

- This irrationality was also seen when the utilisation of ARBs and their expenditure was examined in the largest hospital in Chongqing District of China and one of the largest hospitals in South West China

- The utilisation of ARBs increased substantially between 2006 and 2012. However, the utilisation patterns for different originator ARBs was variable and did not reflect their procured prices. There was also typically low utilisation of cheaper generics versus originators

- The reduction in the procured prices for generics over time were similar to those seen among some Western European countries. However, there are still considerable opportunities to further lower prices of generics as well as enhance their utilisation vs. originators 
- Introducing supply- and demand-side measures in China similar to Western European countries would enhance the potential for China to achieve its desired goal of universal coverage by 2020. However, this will need substantial changes to the remuneration system for physicians and hospitals to achieve this

\section{Acknowledgments and conflicts of interest}

We thank the publishing company of the Journal of China Pharmacy for providing us with the datasets used in this study.

Part of the analysis and writing of this paper was supported by a grant from Karolinska Institutet. There are no additional funding sources.

The authors declare that they have no conflicts of interest apart from those stated. No writing assistance was utilized in the production of this manuscript.

\section{References}

* Of interest, ${ }^{* *}$ Of considerable interest

1. Godman B, Bennie M, Baumgärtel $C$ et al. Essential to increase the use of generics in Europe to maintain comprehensive healthcare? Farmeconomia: Health Economics and Therapeutic Pathways 2012, 13 (Suppl 3):5-20.

2. Garattini S, Bertele V, Godman B et al. Enhancing the rational use of new medicines across European healthcare systems - A Position Paper. Eur Jn Clinical Pharmacology 2008; 64:1137-1138

3. Godman B, Wettermark B, van Woerkom M, Fraeyman J, Alvarez-Madrazo S, Berg C, et al. Multiple policies to enhance prescribing efficiency for established medicines in Europe with a particular focus on demand-side measures: findings and future implications. Frontiers in pharmacology. 2014;5:106.

${ }^{*}$ Good paper summarising the influence of different demand-side measures across classes in Europe

4. Godman B, Wettermark B, Hoffman M et al. Multifaceted national and regional drug reforms and initiatives in ambulatory care in Sweden; global relevance. Expert Rev Pharmacoeconomcis Outcomes Research 2009; 9:65-83

5. Godman B, Shrank W, Andersen M et al. Comparing policies to enhance prescribing efficiency in Europe through increasing generic utilisation: changes seen and global implications. Expert Rev. Pharmacoeconomics Outcomes Res 2010; 10: 707-722

6. Vončina L, Strizrep T, Godman B et al. Influence of demand-side measures to enhance reninangiotensin prescribing efficiency in Europe: implications for the future. Expert Rev. Pharmacoecon. Outcomes Res. 2011; 11: 469-79

7. Bennie M, Godman B, Bishop I, Campbell S. Multiple initiatives continue to enhance the prescribing efficiency for the proton pump inhibitors and statins in Scotland. Expert Review Pharmacoeconomics and Outcomes Research 2012; 12: 125-130

8. van Woerkom M, Piepenbrink H, Godman B et al. Ongoing measures to enhance the efficiency of prescribing of PPIs and statins in the Netherlands; influence and future implications. Journal of Comparative Effectiveness Research 2012, 1:527-38.

* Documents very low prices for generic omeprazole and simvastatin in the Netherlands - providing examples to other countries

9. Sakshaug S, Furu K, Karlstad O et al. Switching statins in Norway after new reimbursement policy - a nationwide prescription study. Br J Clin Pharmacol 2007; 64: 476-81 
10. Godman B, Wettermark B, Miranda J et al. Influence of multiple initiatives in Sweden to enhance ARB prescribing efficiency following generic losartan; findings and implications for other countries. International Journal of Clinical Practice 2013, 67: 853-862.

* Documents the impact of multiple demand-side measures in Sweden to enhance the prescribing of generic losartan once available

11. Hesse U, Godman B, Petzold M, et al. Impact of Delisting ARBs, apart from Losartan, on ARB Utilisation Patterns in Denmark: Implications for Other Countries. App Health Econ Health Policy 2013; 11:677-685

12. Martikainen $\mathrm{J}$, Saastamoinen $\mathrm{L}$, Korhonen $\mathrm{M}$ et al. Impact of restricted reimbursement on the use of statins in Finland - A register-based study. Medical Care 2010; 48:761-6

13. Fraeyman J, Van Hal G, De Loof H, Remmen R, De Meyer GR, Beutels P. Potential impact of policy regulation and generic competition on sales of cholesterol lowering medication, antidepressants and acid blocking agents in Belgium. Acta Clin Belg. 2012 May-Jun;67(3):160-71

14. Moon J, Flett A, Godman B, Grosso A, Wierzbicki A. Getting better value from the NHS drug budget. BMJ 2011; 342: 30-2

15. Martin A, Godman B, Miranda J et al. Measures to improve angiotensin receptor blocker prescribing efficiency in the UK: findings and implications. Jn Comparative Effect Res 2014; 3(1): $41-$ 51

* Documents the impact of a successful therapeutic switching programme to enhance the prescribing of losartan in one UK Primary Care group and associated savings

16. Norman $\mathrm{C}$, Zarrinkoub R, Hasselström $\mathrm{J}$ et al. Potential savings without compromising the quality of care. Int J Clin Pract 2009: 63:1320-26

17. Usher-Smith J, Ramsbottom T, Pearmain H, Kirby M. Evaluation of the clinical outcomes of switching patients from atorvastatin to simvastatin and losartan to candesartan in a primary care setting: 2 years on. Int J Clin Pract 2008; 62,480-4

18. Wettermark B, Person A, Juhasz-Haverinen M, Veg A, Edlert M, Törnwall-Bergendahl G, Almkvist $\mathrm{H}$, Godman $\mathrm{B}$ et al. Financial incentives linked to self-assessment of prescribing patterns - a new approach for quality improvement of drug prescribing in primary care. Quality in Primary Care 2009;17:179-89

19. Gustafsson LL, Wettermark B, Godman B et al. The "Wise List"- A comprehensive concept to select, communicate and achieve adherence to recommendations of essential drugs in ambulatory care in Stockholm. Basic \& Clinical Pharmacology \& Toxicology 2011; 108:224-233

${ }^{*}$ Documents the influence of a long-term programme to enhance the rational use of medicines in a region through voluntary adherence to a selected list of medicines

20. Kaplan WA, Ritz LS, Vitello M, Wirtz VJ. Policies to promote use of generic medicines in low and middle income countries: A review of published literature, 2000-2010. Health Policy, 2012, 106(3): 211-224.

21. Cameron A, Mantel-Teeuwisse AK, Leufkens HGM, Laing RO. Switching from originator brand medicines to generic equivalents in selected developing countries: how much could be saved?. Value in Health, 2012:664-673.

22. Zeng W. A price and use comparison of generic versus originator cardiovascular medicines: a hospital study in Chongqing, China. BMC Health Services Research 2013 13:390

** Original paper discussing utilisation and expenditure of generics in this District 
23. Lu C, Ross-Degnan D, Stephens $P$, Liu B, Wagner A. Changes in use of antidiabetic medications following price regulations in China (1999-2009). JPHSR 2013, 4: 3-11

24. Li X, Zhang W. The impacts of health insurance on health care utilization among the older people in China. Social Science \& Medicine, 2013.85:59-65

25. Meng $Q, X u L$, Zhang $Y$, et al. Trends in access to health services and financial protection in China between 2003 and 2011: a cross-sectional study. The Lancet. 2012; 379(9818):805-14.

26. Barber S, Huang B, Santoso B, Laing R, Paris V, Wu C. The reform of the essential medicines system in China: a comprehensive approach to universal coverage. J Glob Health. 2013 June; 3(1): 010303

27. Sun J. International experiences of promoting generics use and its implications to China. Journal of Evidence-Based Medicine 2013; 6: 74-80

28. Li L. The challenges of healthcare reforms in China. P u b I i c Health 125 ( 2011 ) 6e8

29. Ling R, Liu F, Lu X, Wang W. Emerging issues in public health: A perspective on China's healthcare system. Pu b I c He a I t h 125 ( 20111$) 9$ e1 4

30. Yu X, Li C, Shi Y, Yu M: Pharmaceutical supply chain in China: Current issues and implications for health system reform. Health Policy 2010, 97:8-15.

31. Mao W, Tang S, Chen W. Does perverse economic incentive lead to the irrational uses of medicines? Expert Rev. Pharmacoecon. Outcomes Res. 13(6), 693-696 (2013)

* Good paper discussing some of the perverse incentives in China and their implications

32. SunQ, Santoro M, Meng Q, Liu C, Eggleston K. Pharmaceutical Policy In China. Health Affairs 2008; $27: 1042-50$

33. Tao T, Xu C, Hu M, Liao W, Jiang X: Analysis of Chinese pharmaceutical price policy from 1997 to 2011. Chin J Health Policy 2011, 4:46-52.

34. Godman B, Bishop I, Finlayson A E, et al. Reforms and initiatives in Scotland in recent years to encourage the prescribing of generic drugs, their influence and implications for other countries. Expert Rev Pharmacoeconomics Out Res, 2013, 13(4): 469-482.

35. Chen Y, Schweitzer SO: Issues in drug pricing, reimbursement, and access in China with references to other Asia-Pacific region. Value Health 2008;11:124-29.

36. Wagstaff A, Lindelow M. Can insurance increase financial risk? The curious case of health insurance in China. J Health Econ. 2008 Jul;27(4):990-1005

37. Jingang A. Which future for doctors in China? The Lancet 2013; 382: 936-7

38. Meng $Q$ et al. The impact of China's retail drug price control policy on hospital expenditures: a case study in two Shandong hospitals. Health Policy Plan 2005; 20: 185-196.

39. Liu L, Lu Z, Zhang X. Analysis of Rational use of Drugs in Community Health Service Facilities. Chinese Health Econ. 2009; 28(4): 45-7

40. Grimshaw J, Campbell M, Eccles M et al. Experimental and quasi-experimental designs for evaluating guidelines implementation strategies. Family Practice 2000; 17, S11-S16 
41. Bucsics A, Godman B, Burkhardt T et al. Influence of lifting prescribing restrictions for losartan on subsequent sartan utilization patterns in Austria: implications for other countries. Expert review of pharmacoeconomics \& outcomes research, 2012, 12(6): 809-819.

42. Simoens S, De Bruyn K, Miranda J et al. Measures to enhance ARB prescribing efficiency in Belgium following generic losartan: impact and implications for the future. J Pharm Health Serv Res. 2013;4:173-81..

43. Bennie M, Bishop I, Godman B et al. Are prescribing initiatives readily transferable across classes: the case of generic losartan in Scotland? Quality in Primary Care 2013;21:7-15

44. Teng L, Xin HW, Blix HS, Tsutani K. Review of the use of defined daily dose concept in drug utilisation research in China. Pharmacoepidemiol Drug Saf. 2012 Oct;21(10):1118-24

45. Vogler S, Zimmermann N, Leopold C, de Joncheere K. Pharmaceutical policies in European countries in response to the global financial crisis. Southern Med Review 2011;4(2):22-32.

46. Sermet C, Andrieu V, Godman B, Van Ganse E, Haycox A, Reynier JP. Ongoing pharmaceutical reforms in France; implications for key stakeholder groups. Applied Health Economics and Health Policy 2010; 8: 7-24

47. Rønning M, Blix HS, Harbø BT, Strøm H. Different versions of the anatomical therapeutic chemical classification system and the defined daily dose--are drug utilisation data comparable? Eur $\mathrm{J}$ Clin Pharmacol 2000; 56: 723-7

48. Vlahovic-Palcevski V, Gantumur M, Radosevic N et al. Coping with changes in Defined Daily Dose in longitudinal drug consumption databases. Pharm World Sci 2010; 32:125-9

49. Reynolds L, McKee M. Serve the people or close the sale? Profit-driven overuse of injections and infusions in China's market-based healthcare system. Int. J. Health Plann. Mgmt 2011: 26: 449-70

** Good paper demonstrating the influence of perverse incentives in China and their implications

50. Björkhem-Bergman J, Andersen-Karlsson E, Laing R et al. Interface management of pharmacotherapy. Joint hospital and primary care drug recommendations. Eur J Clin Pharmacol 2013; 69 (Suppl 1):S73-S78

51. Karadis K, Tomson G, Wettermark B et al. The establishment and expansion of an innovative centre for rational pharmacotherapy - determinants and challenges. International Journal of Health Planning and Management Published online in Wiley Online Library 2013. DOI: 10.1002/hpm.2202

52. Jian W-Y, Lu M, Cui T, Hu M. Evaluating performance of local case-mix system by international comparison: a case study in Beijing, China. Int. J. Health Plann. Mgmt 2011: 26: 471-81

53. Yu S-Y, Yang, B-M Kim J-H. New Anti-Rebate Legislation in South Korea. Appl Health Econ Health Policy (2013) 11:311-318

54. Roehr B. Drug companies will have to report all payments to US doctors from March 2014. BMJ 2013;346

55. Heran BS, Wong MM, Heran IK, Wright JM. Blood pressure lowering efficacy of angiotensin receptor blockers for primary hypertension. Cochrane Database Syst Rev 2008(4):CD003822

56. Svanstrom H, Pasternak B, Hviid A. Association of treatment with losartan vs candesartan and mortality among Patients with heart failure. JAMA 2012;307:1506-12

57. Godman B, Bennie M, Bucsics A et al. Variable approaches in Europe to the availability of generic losartan; implications for the future. Clinical Therapeutics 2013; 35(8S); e36-7 


\section{Web based references}

101. OECD (2011), "Pharmaceutical expenditure", in OECD, Health at a Glance 2011: OECD Indicators, OECD Publishing. doi: 10.1787/health glance-2011-63-en Available via URL: http://www.oecd.org/els/health-systems/49105858.pdf [Accessed December 2013]

102. National Health and Family Planning Commission of China: China Health Statistics Annuals 2011. Available via URL: http://wsb.moh.gov.cn/htmlfiles/zwgkzt/ptjnj/year2011/index2011.html [Accessed December 2013]

103. Yinan B. Radical treatment for healthcare. China Daily. Available via URL: www.chinadaily.com.cn/china/2010-09/16/content_11309825.htm (Accessed January 2013)

104. WHO: Guidelines for ATC classification and DDD assignment. In Oslo: WHO Collaborating Centre for Drug Statistics Methodology. www.whocc.no [Accessed December 2013]

105. World Health Organization (WHO). Introduction to Drug Utilisation Research. WHO International Working Group for Drug Statistics Methodology, WHO Collaborating Centre for Drug Statistics Methodology, WHO Collaborating Centre for Drug Utilization Research and Clinical Pharmacological Services. ISBN 924156234 X (NLM classification: WB 330) Available via URL: http://www.who.int/medicines/areas/quality safety/safety efficacy/Drug\%20utilization\%20research.pd $\underline{\text { f }}$ Accessed December 2013].

106. NICE updates its guidance on the management of hypertension. MeReC 10 October 2011. Available via URL: http://www.npc.nhs.uk/rapidreview/?p=4470 [Accessed December 2013]

107. Chinese Food and Drug Administration. Available via URL:

http://app1.sfda.gov.cn/datasearch/face3/base.jsp?tableld=25\&tableName=TABLE25\&title=\%E5\%9B \%BD\%E4\%BA\%A7\%E8\%8D\%AF\%E5\%93\%81\&bcld=124356560303886909015737447882

[Accessed December 2013] 